\title{
Effect of increased calcium consumption from fat-free milk in an energy- restricted diet on the metabolic syndrome and cardiometabolic outcomes in adults with type 2 diabetes mellitus: a randomised cross-over clinical trial
}

\author{
Junia M. G. Gomes ${ }^{1 *}$, Jorge d. A. Costa ${ }^{2}$ and Rita C. G. Alfenas ${ }^{2}$ \\ ${ }^{1}$ Instituto Federal do Sudeste de Minas Gerais - Campus Barbacena, Rua Monsenhor José Augusto, 204, Bairro São José, \\ Barbacena, Minas Gerais, CEP 36205-018, Brazil \\ ${ }^{2}$ Nutrition and Health Department, Federal University of Viçosa (Universidade Federal de Viçosa), Avenida PH Rolfs, s/n, \\ Viçosa, Minas Gerais, CEP 36570-000, Brazil
}

(Submitted 17 April 2017 - Final revision received 16 November 2017 - Accepted 15 December 2017)

\section{Abstract}

We investigated the effects of high-Ca fat-free milk phase (MD) (prescription of approximately $1500 \mathrm{mg}$ of $\mathrm{Ca} / \mathrm{d}$ ) $v$. low-Ca phase (CD) (prescription of approximately $800 \mathrm{mg}$ of $\mathrm{Ca} / \mathrm{d}$ ) in an energy-restricted diet on the metabolic syndrome (MetS) and cardiometabolic measures in individuals with type 2 diabetes mellitus (T2DM) and low habitual Ca consumption $(<600 \mathrm{mg} / \mathrm{d})$. In this randomised cross-over design, fourteen adults with T2DM (49.5 (SD 8.6) years, BMI 29.4 (SD 4.5$) \mathrm{kg} / \mathrm{m}^{2}$ ) consumed either MD or CD for 12 weeks, with a washout of 18 weeks between phases. A breakfast shake containing $700 \mathrm{mg}$ (MD) or $6.4 \mathrm{mg}$ (CD) of Ca was consumed in the laboratory. In addition, energyrestricted diets were prescribed $(800 \mathrm{mg}$ of dietary $\mathrm{Ca} / \mathrm{d}$ ). Waist circumference (WC), fasting glucose, fasting TAG, systolic (SBP) and diastolic blood pressure (DBP), fasting total cholesterol, fasting LDL-cholesterol, fasting HDL-cholesterol, HDL:LDL ratio, HDL:TAG ratio and lipid accumulation product (LAP) index were assessed at baseline and after each phase. Ca consumption during the study was equivalent to $1200 \mathrm{mg} / \mathrm{d}$ during MD and $525 \mathrm{mg} / \mathrm{d}$ during CD. There was a greater reduction in WC, SBP, DBP and LAP index after MD compared with CD. HDL:LDL ratio increased and total cholesterol, LDL-cholesterol, SBP, DBP and LAP index decreased only in MD. The consumption of approximately $1200 \mathrm{mg}$ of $\mathrm{Ca} / \mathrm{d}$ (700 mg from fat-free milk $+500 \mathrm{mg}$ from other dietary sources) associated with an energy-restricted diet decreased some of the MetS components and cardiometabolic measures in adults with T2DM.

Key words: Calcium: Dairy products: Diets: Metabolic syndrome: CVD: Lipids: Blood pressure

Dairy products are sources of nutrients and bioactive compounds, which may reduce inflammation and oxidative stress, besides favouring glycaemic control and body weight loss ${ }^{(1)}$. Low-fat dairy products are an excellent source of protein, $\mathrm{Ca}$, $\mathrm{Zn}, \mathrm{P}, \mathrm{Mg}$ and vitamin $\mathrm{D}^{(2)}$. Milk proteins, particularly whey protein, seem to have insulinotrophic, hypolipidaemic, antihypertensive and anti-inflammatory properties ${ }^{(2)}$. Increased Ca consumption has been associated with beneficial effects on body weight ${ }^{(3)}$, blood pressure $(\mathrm{BP})^{(4)}$ and type 2 diabetes mellitus (T2DM) ${ }^{(5)}$. Other micronutrients of dairy products, such as vitamin $\mathrm{D}, \mathrm{Zn}, \mathrm{P}$ and $\mathrm{Mg}$, are associated with lower T2DM and CVD risk ${ }^{(2)}$.

Large studies, such as the Multi-Ethnic Study of Atherosclerosis, have shown inverse associations between low-fat dairy consumption and inflammation and oxidative stress biomarker concentrations, which play major roles in the onset and development of the metabolic syndrome (MetS) and its components ${ }^{(6)}$. Increased dairy consumption has also been associated with lower incidence of the MetS and $\mathrm{T}_{2} \mathrm{DM}^{(1)}$. Dairy products seem to modulate some cardiovascular risk factors (e.g. insulin response, dyslipidaemia, oxidative stress and inflammation markers, BP and so on), but the association between dairy consumption and CVD is controversial ${ }^{(1,7)}$. Apparently, the consumption of energy-restricted diets containing low-fat dairy products seems be more efficient in reducing body weight, body fat mass, waist circumference (WC) and BP compared with whole dairy and non-energyrestricted diets ${ }^{(8,9)}$.

In a review study involving data from randomised clinical trials (RCT), Pasin \& Comerford ${ }^{(10)}$ concluded that dairy foods might improve glycaemic status in adults with T2DM. However, these results were observed in acute studies or in long-term

Abbreviations: BP, blood pressure; CD, low-calcium phase; DBP, diastolic blood pressure; MetS, metabolic syndrome; MD, high-calcium fat-free milk phase; LAP, lipid accumulation product; MET, metabolic equivalents of task; PAL, physical activity levels; PTH, parathyroid hormone; RCT, randomised clinical trials; SBP, systolic blood pressure; T2DM, type 2 diabetes mellitus; WC, waist circumference.

* Corresponding author: J. M. G. Gomes, fax +55 31 38992541, email junianut@yahoo.com.br 
studies that used probiotic yogurt for the intervention group ${ }^{(10)}$. The microorganisms present in yogurt can improve systemic disorders, such as T2DM, dyslipidaemia, inflammation and oxidative stress $^{(10)}$. Therefore, the effects of other dairy products (i.e. milk) on metabolic profile of T2DM adults need to be better explored.

Although previous studies have investigated the effect of dairy products on body weight and glycaemic control ${ }^{(1,10-12)}$, to the best of our knowledge no other RCT has assessed the effect of increased $\mathrm{Ca}$ consumption from fat-free milk associated with an energy-restricted diet on the MetS and cardiometabolic outcomes in adults with T2DM. Considering the relevance of dietary treatment on T2DM and the MetS, it is necessary to verify whether diets containing high $\mathrm{Ca}$ from fat-free milk have beneficial effects on these disorders. Therefore, this study aimed to investigate the effect of increased $\mathrm{Ca}$ consumption from fat-free milk in the context of an energy-restricted diet on MetS components and cardiometabolic measures in adults with T2DM.

\section{Methods}

This study was conducted according to the Declaration of Helsinki guidelines, and all procedures involving human participants were approved by the Committee of Ethics in Human Research of the Federal University of Viçosa/Brazil. Written informed consent was obtained from all subjects. The present trial was registered at www.clinicaltrials.gov (ID no. NCT02377076).

\section{Participants}

Study participants were recruited through public advertisements in the town of Viçosa, Minas Gerais, Brazil. Recruitment was initiated on 2 February 2014, and ended on 3 June 2015, when the required number of subjects for the study was obtained. Eligible subjects were adults of both genders with T2DM treated with only diet or with diet plus oral hypoglycaemic agents, who had the $\operatorname{MetS}^{(13)}$, had low habitual Ca intake $(<600 \mathrm{mg} / \mathrm{d})$, were between 20 and 59 years of age, had a dietary restraint $<14^{(14)}$, had light to moderate physical activity levels (PAL) ${ }^{(15)}$ and had T2DM for at least 1 year.
Exclusion criteria were the following: (1) smoking; (2) use of Ca, vitamin D, Zn or Mg supplements or medication that affects the metabolism of these micronutrients; (3) use of drugs (except hypoglycaemic drugs), herbs or diets for weight loss; (4) on hormone replacement therapy; (5) menopause or post menopause; (6) recent weight gain or loss $( \pm 5 \mathrm{~kg})$ over the previous 3 months; (7) recent change in PAL over the previous three months; (8) aversion or intolerance to the shakes provided during the study; (9) alcohol consumption of more than $12 \mathrm{~g} / \mathrm{d}$ for women and $24 \mathrm{~g} / \mathrm{d}$ for men; (10) eating disorders; (11) endocrine (except T2DM and obesity), kidney or liver pathology; (12) Ca malabsorption; (13) history of recurrent nephrolithiasis; (14) history of gastric surgery or current gastric disease including gastroparesis; (15) consumption of more than $350 \mathrm{mg} / \mathrm{d}$ of caffeine; (16) pregnancy or lactation; (17) anaemia; and (18) changes in medication type or dosage during the study.

\section{Study design}

This is a randomised, cross-over clinical trial of two 12-week phases separated by a washout period of 8 weeks. Participants were initially randomly assigned by simple randomisation procedures (computerised random numbers) to high-Ca fat-free milk phase (MD) (equivalent to approximately 3 fat-free milk portions) or low-Ca control phase (CD) in a 1:1 ratio. Participants and data analysts were blinded. An energy-restricted diet (restriction of $2092 \mathrm{~kJ} / \mathrm{d}(500 \mathrm{kcal} / \mathrm{d})$ ) containing $800 \mathrm{mg}$ of dietary $\mathrm{Ca} / \mathrm{d}$ was prescribed. Subjects daily consumed in the laboratory a breakfast shake containing $700 \mathrm{mg}$ (MD) (equivalent to approximately three servings of fat-free milk) or $6.4 \mathrm{mg}$ (CD) of $\mathrm{Ca}$. All other meals were consumed in free-living condition in both phases. Participants were instructed to maintain constant PAL and medication use during the study.

$\mathrm{PAL}$, nutrient and energy intake, MetS components (WC, fasting glucose, fasting TAG, HDL-cholesterol and BP) ${ }^{(14)}$, other cardiometabolic risk factors (total cholesterol, LDL-cholesterol, VLDL-cholesterol, insulin, HDL:LDL ratio, HDL:TAG ratio and lipid accumulation product (LAP) index)) and $\mathrm{Ca}$ homoeostasis markers (serum total $\mathrm{Ca}, \mathrm{P}, \mathrm{Mg}$, parathormone (PTH) and 25-hydroxyvitamin D concentrations) were evaluated at baseline and after 12 weeks of each dietary phase (Fig. 1).

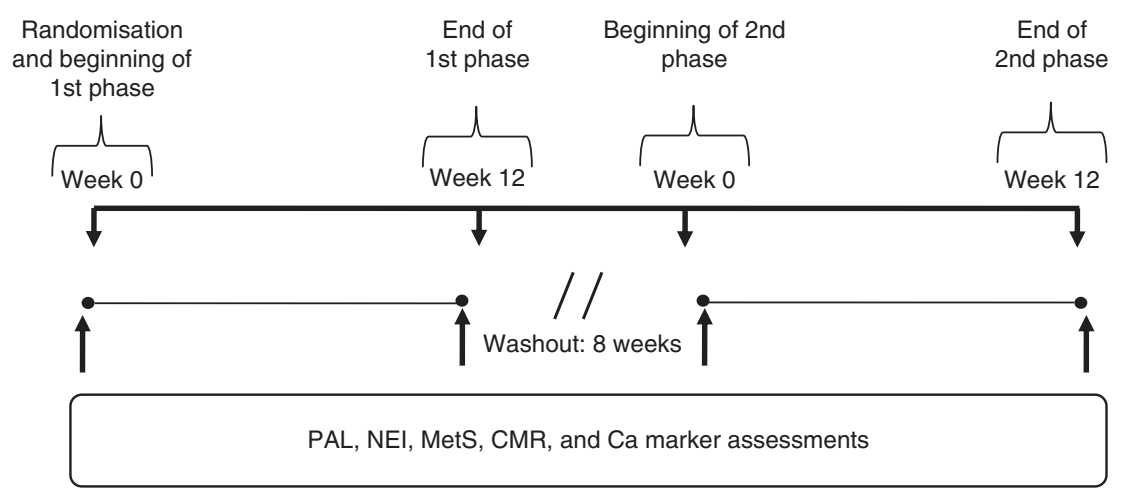

Fig. 1. Study design. Physical activity level (PAL), nutrient and energy intake (NEI), metabolic syndrome (MetS) components, cardiometabolic risk factors (CMR) and calcium homoeostasis markers (Ca markers) were assessed before and after each phase (fat-free milk and control phases) $(n$ 14). 


\section{Physical activity assessment}

PAL was assessed using the long-format International Physical Activity Questionnaire (IPAQ), version 6, validated for the Brazilian adult population ${ }^{(15)}$. The total amount of time spent in physical activity per week was estimated by the sum of each item (i.e. vigorous intensity, moderate intensity and walking) obtained from IPAQ. Total weekly physical activity (metabolic equivalents of task (MET)-min/week) was estimated by adding the products of reported time for each item by a MET value specific for each physical activity category. PAL were classified as follows: vigorous $\mathrm{PAL}=8.0 \mathrm{MET}$, moderate $\mathrm{PAL}=4.0 \mathrm{MET}$ and walking $=3.3$ MET $^{(15)}$. To verify possible changes in PAL, IPAQ was applied at baseline and at end of each phase (CD and MD).

\section{Nutrient and energy intake}

Habitual Ca consumption was assessed at baseline using a quantitative FFQ validated for assessing food intake of Brazilian adults with chronic diseases ${ }^{(16)}$. Food intake at baseline and after 12 weeks of each experimental phase was assessed using 3 nonconsecutive days ( 2 weekdays and a weekend day) food records. Participants were trained to keep free-feeding dietary records at baseline to increase data reliability. Each dietary record was reviewed with the participants to ensure accuracy and completeness. Moreover, a food portion photo album was used to improve data quality ${ }^{(17)}$. The amounts of foods registered in household measures were converted into appropriate units for energy intake, macronutrients, $\mathrm{Ca}, \mathrm{P}, \mathrm{Mg}, \mathrm{Zn}$ and dietary fibre intake analyses using DietPro, version 5.1i (July 2015). A single dietitian analysed the food records. The revised Goldberg method was used to categorise misreported reported energy intake $(\mathrm{rEI})^{(18)}$. Participants were classified as under-reporters, acceptable reporters or over-reporters using the ratio of rEI to total energy expenditure (TEE). TEE was calculated from the product of $\mathrm{BMR}^{(19)}$ and PAL. PAL was assumed to be 1.55 (light activity) for all subjects ${ }^{(19)}$. A $95 \%$ CI was calculated, and individuals who fall outside of the $95 \%$ CI were classified as underor over-reporters and were excluded from statistical analysis. In the present study, none was excluded for that reason.

\section{Dietary intervention}

Each participant's daily energy requirement was based on the estimated energy requirement (EER) ${ }^{(20)}$. EER was calculated by using the dietary reference intake predictive equations developed by the Institute of Medicine ${ }^{(20)}$. In these equations, a physical activity coefficient was applied according to the subjects' PAL. Then, $2092 \mathrm{~kJ} / \mathrm{d}(500 \mathrm{kcal} / \mathrm{d})$ was subtracted for dietary restriction. Diets were prescribed according to the American Diabetes Association nutrition recommendations ${ }^{(21)}$ and considering the nutritional composition of the breakfast shakes provided during the study. Nutrient composition was calculated by DietPro software or according to food labels. MD- and CDprescribed diets presented similar contents of macronutrients, vitamin $\mathrm{D}, \mathrm{P}, \mathrm{Mg}, \mathrm{Zn}$ and dietary fibre. MD-prescribed diet contained $1500 \mathrm{mg}$ and $\mathrm{CD}$ had $800 \mathrm{mg}$ of $\mathrm{Ca} / \mathrm{d}$. Participants were given meal patterns and one list discriminating the types of foods to help them in their food choices. The foods were grouped in that list considering their energy and Ca content. Participants received individualised nutritional counselling every 2 weeks to increase prescribed diet adherence. An experienced dietitian assessed eating patterns and habitual food intake, exercise and medication patterns. Nutrition counselling was provided to stimulate healthy eating habits, including adequate consumption of dietary fibre and water, besides avoiding alcohol consumption and so on, according to ADA recommendations ${ }^{(21)}$. Energy and nutrient requirements were adjusted according to the nutritional requirement of each subject right before the beginning of the second experimental phase. In the washout period, participants were told to maintain their normal diet, which was assessed through three non-consecutive days (two weekdays and a weekend day) food records.

\section{Breakfast shakes}

In all, twelve shake types (six for MD and six for CD experimental phase) were developed for consumption at breakfast. Shakes flavours (frozen fruit pulps or chocolate powder) were the same for both phases. They presented similar macronutrient, vitamin $\mathrm{D}, \mathrm{Na}$ and dietary fibre contents (Table 1). Shakes were also visually very similar, ensuring participants remained unaware of phase differences and the purpose of

Table 1. Ingredients and nutrient composition of the breakfast meals according to study phases $†$

(Mean values and standard deviations)

\begin{tabular}{|c|c|c|c|c|}
\hline \multirow[b]{3}{*}{ Ingredients ( 1 serving of $500 \mathrm{ml}$ ) } & \multicolumn{4}{|c|}{ Study phase } \\
\hline & \multicolumn{2}{|c|}{$\mathrm{MD}(n 6)$} & \multicolumn{2}{|c|}{$\mathrm{CD}(n 6)$} \\
\hline & Mean & SD & Mean & SD \\
\hline Fat-free milk powder (g) & \multicolumn{2}{|c|}{$47 \cdot 0$} & \multicolumn{2}{|l|}{0.0} \\
\hline Sugar $(g)$ & \multicolumn{2}{|c|}{0.0} & \multicolumn{2}{|c|}{23.5} \\
\hline Whey protein $(\mathrm{g})$ & \multicolumn{2}{|c|}{0.0} & \multicolumn{2}{|c|}{18.02} \\
\hline Sodium chloride $(\mathrm{g})$ & \multicolumn{2}{|c|}{0.0} & \multicolumn{2}{|c|}{0.7} \\
\hline Micronutrient supplement (mg)‡ & \multicolumn{2}{|c|}{0.0} & \multicolumn{2}{|l|}{4.0} \\
\hline $\begin{array}{l}\text { Frozen fruit pulps or } \\
\text { chocolate powder }(\mathrm{g}) \S\end{array}$ & \multicolumn{2}{|c|}{100 or 10} & \multicolumn{2}{|c|}{100 or 10} \\
\hline Water (ml) & \multicolumn{2}{|c|}{250} & \multicolumn{2}{|l|}{250} \\
\hline \multicolumn{5}{|l|}{ Nutrient composition } \\
\hline Energy $(\mathrm{kJ})$ & $827 \cdot 6$ & $46 \cdot 4$ & 828.4 & $46 \cdot 4$ \\
\hline Energy (kcal) & $197 \cdot 8$ & $11 \cdot 1$ & $198 \cdot 0$ & $11 \cdot 1$ \\
\hline Carbohydrate (g) & 31.9 & 2.9 & 31.9 & 2.9 \\
\hline Fibre $(\mathrm{g})$ & 1.9 & $2 \cdot 2$ & 1.9 & $2 \cdot 2$ \\
\hline Protein $(\mathrm{g})$ & $17 \cdot 1$ & 0.2 & $17 \cdot 1$ & 0.2 \\
\hline Fat $(\mathrm{g})$ & 0.1 & 0.3 & 0.1 & 0.3 \\
\hline $\mathrm{Ca}(\mathrm{mg})$ & $710 \cdot 5$ & $3 \cdot 7$ & $6 \cdot 4^{\star \star *}$ & $3 \cdot 7$ \\
\hline $\mathrm{Fe}(\mathrm{mg})$ & $10 \cdot 0$ & 0.1 & $10 \cdot 1$ & 0.1 \\
\hline$P(m g)$ & 799.5 & 7.8 & $13 \cdot 7^{\star \star \star}$ & 7.4 \\
\hline $\mathrm{Mg}(\mathrm{mg})$ & $58 \cdot 9$ & 3.9 & $7 \cdot 8^{* * *}$ & 3.9 \\
\hline $\mathrm{Na}(\mathrm{mg})$ & $280 \cdot 9$ & 3.3 & 280.9 & 3.3 \\
\hline $\mathrm{Zn}(\mathrm{mg})$ & 1.91 & $0 \cdot 1$ & $0 \cdot 12^{\star \star \star}$ & $0 \cdot 1$ \\
\hline Vitamin A $(\mu \mathrm{g})$ & 423.0 & 0.0 & 423.0 & 0.0 \\
\hline Vitamin C (mg) & 163.8 & $243 \cdot 3$ & $163 \cdot 8$ & $243 \cdot 3$ \\
\hline Vitamin D $(\mu \mathrm{g})$ & 3.5 & 0.0 & 3.5 & 0.0 \\
\hline
\end{tabular}

$\mathrm{MD}$, high-calcium fat-free milk diet; $\mathrm{CD}$, low-calcium control diet.

${ }^{\star * \star} P<0.001$ by Student's $t$ test.

† Calculated by DietPro ${ }^{\circledR}$ software or according to food labels.

‡ Micronutrient powder supplement containing Fe (iron chelate) and vitamins A (retinol acetate), $\mathrm{C}$ (ascorbic acid), and $\mathrm{D}_{3}$ (cholecalciferol) prepared by a certified compounding pharmacy.

$\S$ Shakes presented similar flavours (frozen fruit pulps or chocolate powder), total of six different flavours. 
the intervention. High-Ca shakes contained fat-free milk powder (Itambé ${ }^{\circledR}$ enriched with Fe, vitamins A, C and D and Ca) reconstituted in water $(250 \mathrm{ml})$. To ensure similarity to high-Ca shakes, low-Ca shakes contained whey protein $\left(\right.$ BemVital $^{\circledR}$; Diacom), sucrose, sodium chloride $\left(\mathrm{Cisne}^{\circledR}\right)$ and a powder supplement containing Fe (iron chelate) and vitamins A (retinol acetate), $\mathrm{C}$ (ascorbic acid) and $\mathrm{D}_{3}$ (cholecalciferol). The powder supplement was prepared by a certified compounding pharmacy. Shakes were prepared by mixing all the ingredients in a blender right before ingestion. Breakfast shakes flavours were offered in random order, according to the study phase.

Subjects daily consumed a shake in the laboratory for 84 consecutive days (12 weeks) in each phase. In case any subject eventually could not come to the laboratory, the shake was consumed in their homes/ jobs. The powdered ingredients (Table 1) were weighed in plastic pots, and the frozen fruit pulps were provided separately. Subjects were instructed on how to blend all the ingredients (mixing powder, water and fruit pulp) used to prepare shakes immediately before ingestion.

\section{Metabolic syndrome components and cardiometabolic measures}

The MetS components assessed were WC, fasting glucose, fasting TAG HDL-cholesterol and BP, using the 'harmonised' version of the $\mathrm{MetS}^{(13)}$. Other cardiometabolic risk factors assessed were total cholesterol, LDL-cholesterol, VLDL-cholesterol, insulin, HDL:LDL ratio, HDL:TAG ratio and LAP index. All assays were done using commercially available kits, according to the manufacturer's instructions.

WC and venous blood samples were obtained after $12 \mathrm{~h}$ of overnight fasting. WC was measured using a flexible inelastic tape at the midpoint between the lowest rib and the iliac crest with a precision of $0.1 \mathrm{~cm}^{(22)}$. Serum glucose, TAG, total cholesterol, HDL-cholesterol and VLDL-cholesterol concentrations were measured by enzymatic colorimetric assay (BS200; Mindray, Diagnostic Laboratory Instrument Inc.). Intra-assay and inter-assay CV were 0.6 and $1.7 \%$ for glucose, 0.4 and $1.3 \%$ for TAG, 0.8 and $1.4 \%$ for total cholesterol and 1.5 and $2.0 \%$ for HDL-cholesterol, respectively. LDL-cholesterol was calculated by the Friedewald formula. Insulin concentrations were measured with an electrochemiluminescence immunoassay (Elecsys Modular-E-170; Roche Diagnostics Systems), with intra-assay and inter-assay CV of 4.2 and $5.5 \%$, respectively. Systolic (SBP) and diastolic BP (DBP) were measured using a calibrated automated sphygmomanometer (HEM-742INT IntelliSense ${ }^{\circledR}$; Omron), after a resting period of at least $10 \mathrm{~min}$ in the sitting position. An appropriate arm cuff was used. Arm position was adjusted so that the cuff was at the level of the right atrium. BP was measured on the dominant arm, every $3 \mathrm{~min}$ for $15 \mathrm{~min}$, at the constant temperature of $22-24^{\circ} \mathrm{C}$. The first value was discarded, and the mean of the last four readings was used in the analysis. HDL/LDL ratio was calculated by dividing HDL-cholesterol by LDL-cholesterol values. HDL:TAG ratio was calculated by dividing HDL-cholesterol by TAG concentrations. The LAP index was calculated as (WC $(\mathrm{cm}])-65) \times($ TAG concentration $(\mathrm{mm}))$ for men, and (WC $(\mathrm{cm})-58) \times($ TAG concentration $(\mathrm{mm}))$ for women ${ }^{(23)}$

\section{Calcium homoeostasis markers}

Serum total Ca concentrations were assessed by Ca arsenazo III method (Mira Plus; Roche Diagnostic Systems), with intra-assay and inter-assay CV of 0.9 and $1.5 \%$, respectively. Serum $\mathrm{P}$ and $\mathrm{Mg}$ concentrations were measured using a colorimetric assay (Bioclin kit; Quibasa Basic Chemical Ltda), with intra-assay and inter-assay CV of 2.7 and $2.5 \%$ for $\mathrm{P}$, and 1.2 and $1.3 \%$ for $\mathrm{Mg}$, respectively. Serum PTH concentrations were measured with an electrochemiluminescence immunoassay (Elecsys Modular-E-170; Roche Diagnostics Systems), with intra-assay and inter-assay CV of $2 \cdot 8$ and $3.3 \%$, respectively. Serum 25 -hydroxyvitamin D levels were determined by chemiluminescent microparticle immunoassay (Architect i2000; Abbott Diagnostics), with intra-assay and interassay CV of $5 \cdot 1$ and $7 \cdot 2 \%$, respectively.

\section{Statistical analysis}

Statistical analyses were conducted using the Statistical Package for Social Sciences for Windows, version 20.0 (IBM). All variables were examined for normality of distribution according to the Shapiro-Wilk test at 5\% significance. Data are expressed as means and standard deviations. An independent-samples $t$ test was conducted to identify possible differences between who started with either MD $(n 7)$ or $\mathrm{CD}(n 7)$ at baseline. To verify the efficacy of the washout period, a paired $t$ test was conducted between the initial baseline data and the post-washout baseline data. Baseline data were calculated before each intervention period. Once the efficacy of the washout period was verified, the initial baseline and post-washout baseline data were combined and the final data from each study arm ( $n$ 14 each for the two phases) were combined. Then, data within sessions were analysed using the paired $t$ test or Wilcoxon signed-rank test, pairing results from the same individual before (baseline) and after (12 weeks) each dietary intervention (CD or MD phase), considering $P$ values $\leq 0.05$ as significant. Data on changes from the baseline over the 12 weeks of the intervention (deltas, i.e. the final value minus the baseline value) were compared between the sessions using the paired $t$ test or Wilcoxon's signed-rank test, with Bonferroni correction for multiple comparisons. The criterion of significance was $P<0 \cdot 025$, two tailed. Sample size was calculated according to the equation reported by Mera et al. ${ }^{(24)}$, considering the glycated $\mathrm{Hb}$ (HbA1C) as the main variable. Our eligible subjects' baseline mean and standard deviation HbA1C values were applied, considering a desirable reduction of $1 \%$ to decrease microangiopathy and neuropathy occurrence ${ }^{(21)}$. The statistical power was set up at $90 \%$. Therefore, and by applying a $P$ value $<0.05$, the sample size required in our study was equivalent to fourteen volunteers per phase.

\section{Results}

\section{Participants}

In all, sixteen subjects met the eligibility criteria. However, fourteen (four men and ten women, BMI of 29.4 (SD 4.5 ) $\mathrm{kg} / \mathrm{m}^{2}$, and 49.5 (sD 8.6) years of age; not on insulin therapy; 5 (SD 2) years duration of diabetes after diagnosis; sedentary) (Tables 2 and 3) completed both phases and were included in the 
Table 2. Food intake presented by the subjects, according to study experimental phase $(n 14)$

(Mean values and standard deviations)

\begin{tabular}{|c|c|c|c|c|c|c|c|c|c|c|c|c|}
\hline & \multicolumn{6}{|c|}{ MD phase } & \multicolumn{6}{|c|}{ CD phase } \\
\hline & \multicolumn{2}{|c|}{ Baseline } & \multicolumn{2}{|c|}{ Final } & \multicolumn{2}{|c|}{ Change from baseline } & \multicolumn{2}{|c|}{ Baseline } & \multicolumn{2}{|c|}{ Final } & \multicolumn{2}{|c|}{ Change from baseline } \\
\hline & Mean & SD & Mean & SD & Mean & SD & Mean & SD & Mean & SD & Mean & SD \\
\hline \multicolumn{13}{|l|}{ Nutrientł } \\
\hline Energy $(\mathrm{kJ} / \mathrm{d})$ & 7301 & 2113 & 7042 & 1745 & -259 & 2100 & 6397 & 1912 & 7179 & 1837 & 778 & 895 \\
\hline Energy $(\mathrm{kcal} / \mathrm{d})$ & 1745 & 505 & 1683 & 417 & -62 & 502 & 1529 & 457 & 1716 & 439 & 186 & 214 \\
\hline Carbohydrate $(\mathrm{g} / \mathrm{d})$ & 224 & 73 & 234 & 53 & 10 & 65 & 209 & 65 & 238 & 58 & 29 & 41 \\
\hline Fibre $(g / d)$ & 17 & 4 & $25^{*}$ & 5 & 7 & 5 & 19 & 7 & $15^{\star}$ & 7 & $-4 \dagger$ & 5 \\
\hline Protein $(\mathrm{g} / \mathrm{d})$ & 69 & 21 & 80 & 21 & 12 & 26 & 66 & 22 & 79 & 23 & 13 & 14 \\
\hline Total fat $(\mathrm{g} / \mathrm{d})$ & 65 & 30 & 44 & 15 & -21 & 33 & 45 & 17 & 45 & 16 & 0 & 13 \\
\hline MUFA (g/d) & 19 & 10 & 12 & 6 & -6 & 12 & 12 & 6 & 13 & 6 & 1 & 4 \\
\hline PUFA (g/d) & 13 & 6 & 8 & 3 & -4 & 7 & 8 & 3 & 8 & 3 & 0 & 3 \\
\hline SFA $(g / d)$ & 17 & 10 & $10^{*}$ & 4 & -7 & 10 & 10 & 5 & 10 & 4 & 0 & 4 \\
\hline $\mathrm{Ca}(\mathrm{mg} / \mathrm{d})$ & 388 & 184 & $1218^{*}$ & 145 & 830 & 178 & 590 & 283 & 525 & 301 & $-65 \dagger$ & 369 \\
\hline$P(\mathrm{mg} / \mathrm{d})$ & 788 & 217 & $1643^{\star}$ & 265 & 855 & 217 & 888 & 288 & 842 & 288 & $-46 \dagger$ & 304 \\
\hline$M g(\mathrm{mg} / \mathrm{d})$ & 174 & 47 & $240^{*}$ & 55 & 65 & 55 & 177 & 66 & 197 & 104 & 20 & 106 \\
\hline $\mathrm{Zn}(\mathrm{mg} / \mathrm{d})$ & 7 & 3 & 9 & 3 & -1 & 2 & 6 & 3 & 6 & 2 & 0 & 2 \\
\hline
\end{tabular}

$\mathrm{MD}$, high-calcium fat-free milk phase; $\mathrm{CD}$, low-calcium control phase.

${ }^{\star} P<0.05$. $P$ value was estimated by paired $t$ test (intra-group comparisons).

$\dagger P<0.025$. $P$ value was estimated by paired $t$ test or Wilcoxon's signed-rank (both with Bonferroni correction for multiple comparisons) (inter-group comparisons).

$\ddagger$ Food intake was assessed by 3-d food records.

Table 3. Metabolic syndrome (MetS) components, other cardiometabolic outcomes and calcium homoeostasis markers presented by the subjects, according to study experimental phase $(n 14)$

(Mean values and standard deviations)

\begin{tabular}{|c|c|c|c|c|c|c|c|c|c|c|c|c|}
\hline & \multicolumn{6}{|c|}{ MD phase } & \multicolumn{6}{|c|}{ CD phase } \\
\hline & \multicolumn{2}{|c|}{ Baseline } & \multicolumn{2}{|c|}{ Final } & \multicolumn{2}{|c|}{ Change from baseline } & \multicolumn{2}{|c|}{ Baseline } & \multicolumn{2}{|c|}{ Final } & \multicolumn{2}{|c|}{ Change from baseline } \\
\hline & Mean & SD & Mean & SD & Mean & SD & Mean & SD & Mean & SD & Mean & SD \\
\hline \multicolumn{13}{|l|}{ MetS components } \\
\hline$W C(\mathrm{~cm})$ & $97 \cdot 0$ & 11.1 & $91.9^{*}$ & 11.7 & $-5 \cdot 1$ & $2 \cdot 4$ & 93.1 & 11.7 & 93.1 & $12 \cdot 2$ & $0.0 \dagger$ & 1.5 \\
\hline Fasting glucose $(\mathrm{mmol} / \mathrm{l})$ & $7 \cdot 3$ & $2 \cdot 4$ & $6 \cdot 8$ & $2 \cdot 2$ & -0.4 & 1.0 & 6.9 & $2 \cdot 3$ & $8 \cdot 3^{*}$ & $3 \cdot 3$ & 1.5 & $2 \cdot 5$ \\
\hline Fasting TAG (mmol/l) & 1.9 & $1 \cdot 1$ & $1 \cdot 7$ & 1.0 & -0.2 & 0.7 & $2 \cdot 0$ & 1.2 & $2 \cdot 1$ & $1 \cdot 2$ & 0.1 & 0.7 \\
\hline HDL-cholesterol (mmol/l) & $1 \cdot 1$ & 0.2 & $1 \cdot 1$ & 0.2 & 0.0 & 0.1 & $1 \cdot 2$ & 0.3 & $1 \cdot 2$ & 0.3 & 0.1 & 0.1 \\
\hline $\mathrm{SBP}(\mathrm{mmHg})$ & $136 \cdot 6$ & $12 \cdot 7$ & $120 \cdot 6^{*}$ & $15 \cdot 8$ & $-16 \cdot 0$ & 11.9 & $124 \cdot 1$ & $10 \cdot 6$ & $123 \cdot 3$ & $12 \cdot 2$ & $-0.8 \dagger$ & $10 \cdot 9$ \\
\hline $\mathrm{DBP}(\mathrm{mmHg})$ & 84.2 & 7.9 & 73.4* & 9.9 & $-10 \cdot 8$ & $8 \cdot 3$ & $77 \cdot 1$ & 8.9 & $75 \cdot 8$ & 7.9 & $-1 \cdot 3 \dagger$ & $7 \cdot 6$ \\
\hline \multicolumn{13}{|l|}{ Other cardiometabolic outcomes } \\
\hline Total cholesterol $(\mathrm{mmol} / \mathrm{l})$ & 4.7 & 0.6 & $4 \cdot 2^{\star}$ & 0.5 & 0.5 & 0.6 & 4.6 & 0.8 & 4.7 & 0.6 & 0.1 & 0.9 \\
\hline LDL-cholesterol (mmol/l) & $2 \cdot 7$ & 0.6 & $2 \cdot 3^{\star}$ & 0.4 & -0.4 & 0.4 & 2.5 & 0.7 & $2 \cdot 5$ & 0.7 & 0.0 & 0.7 \\
\hline VLDL-cholesterol $(\mathrm{mmol} / \mathrm{l})$ & 0.9 & 0.5 & 0.8 & 0.4 & -0.1 & 0.3 & 0.9 & 0.5 & $1 \cdot 0$ & 0.5 & 0.0 & 0.3 \\
\hline HDL:LDL ratio & 0.4 & 0.1 & $0.5^{\star}$ & 0.2 & 0.1 & 0.1 & 0.5 & 0.1 & 0.5 & $0 \cdot 1$ & 0.0 & 0.3 \\
\hline HDL:TAG ratio & 0.4 & 0.3 & 0.4 & 0.3 & 0.0 & 0.1 & 0.4 & 0.3 & 0.4 & 0.5 & 0.1 & 0.2 \\
\hline LAP index (cm.mmol/l) & 71.9 & $42 \cdot 9$ & $23 \cdot 6^{*}$ & $13 \cdot 1$ & $-48 \cdot 4$ & $51 \cdot 1$ & $22 \cdot 2$ & 13.6 & 20.9 & 11.5 & $-1 \cdot 2 \dagger$ & $7 \cdot 4$ \\
\hline \multicolumn{13}{|l|}{ Ca homoeostasis markers } \\
\hline $\mathrm{Ca}(\mathrm{mmol} / \mathrm{l})$ & 0.1 & $2 \cdot 4$ & 0.1 & 0.1 & 0.2 & $2 \cdot 2$ & 0.1 & $2 \cdot 2$ & 0.1 & 0.0 & 0.1 & 0.1 \\
\hline PTH (pmol/l) & 4.6 & $2 \cdot 0$ & $3 \cdot 2^{\star}$ & $1 \cdot 1$ & $-1 \cdot 4$ & 1.4 & 3.4 & $1 \cdot 3$ & $4 \cdot 0$ & 1.4 & $0.6 \dagger$ & $1 \cdot 0$ \\
\hline $25-\mathrm{OH}$ vitamin D $(\mathrm{mmol} / \mathrm{l})$ & 61.4 & $16 \cdot 2$ & $88.9^{*}$ & $29 \cdot 2$ & 27.5 & 25.5 & $75 \cdot 1$ & $19 \cdot 0$ & $69 \cdot 1^{*}$ & $21 \cdot 0$ & $-6.0 \dagger$ & 7.5 \\
\hline $\mathrm{P}(\mathrm{mmol} / \mathrm{l})$ & $1 \cdot 1$ & 0.1 & 1.2 & 0.1 & 0.0 & 0.1 & $1 \cdot 1$ & 0.1 & 1.1 & 0.1 & -0.1 & 0.1 \\
\hline $\mathrm{Mg}(\mathrm{mmol} / \mathrm{l})$ & 0.7 & 0.1 & $0.6^{*}$ & $0 \cdot 1$ & $-0 \cdot 1$ & 0.1 & 0.7 & 0.1 & 0.8 & $0 \cdot 1$ & $0.0 \dagger$ & 0.1 \\
\hline
\end{tabular}

$\mathrm{MD}$, high-calcium fat-free milk phase; $\mathrm{CD}$, low-calcium control (CD) phase; WC, waist circumference; LAP, lipid accumulation product; PTH, parathyroid hormone; 25-OH vitamin D, 25-hydroxyvitamin D.

* $P<0.05$. $P$ value was estimated by paired $t$ test (intra-group comparisons).

$\dagger P<0.025$. $P$ value was estimated by paired $t$ test or Wilcoxon's signed rank (both with Bonferroni correction for multiple comparisons) (inter-group comparisons).

analyses (Fig. 2). The reasons for these drop-outs were difficulties to daily attend the laboratory to consume the shake and owing to the change in the type of medication used.

\section{Dietary intake}

Dietary fibre, Ca and P intake increased in MD compared with CD (inter-group comparison) (Table 2). Ca and P consumption at the end of MD were $232 \%$ (693 mg) and 195.3\% (801 mg) higher, respectively, compared with the end of the CD phase (inter-group comparison) (Table 2 ). The Ca:P ratio was 0.49 and 0.66 at baseline, and 0.74 and 0.62 post treatment for MD and $\mathrm{CD}$, respectively (intra-group comparison). No significant changes in dietary energy, carbohydrate, protein, fat, $\mathrm{Mg}$ and $\mathrm{Zn}$ intake were observed between the two dietary phases (inter-group comparison) (Table 2). 


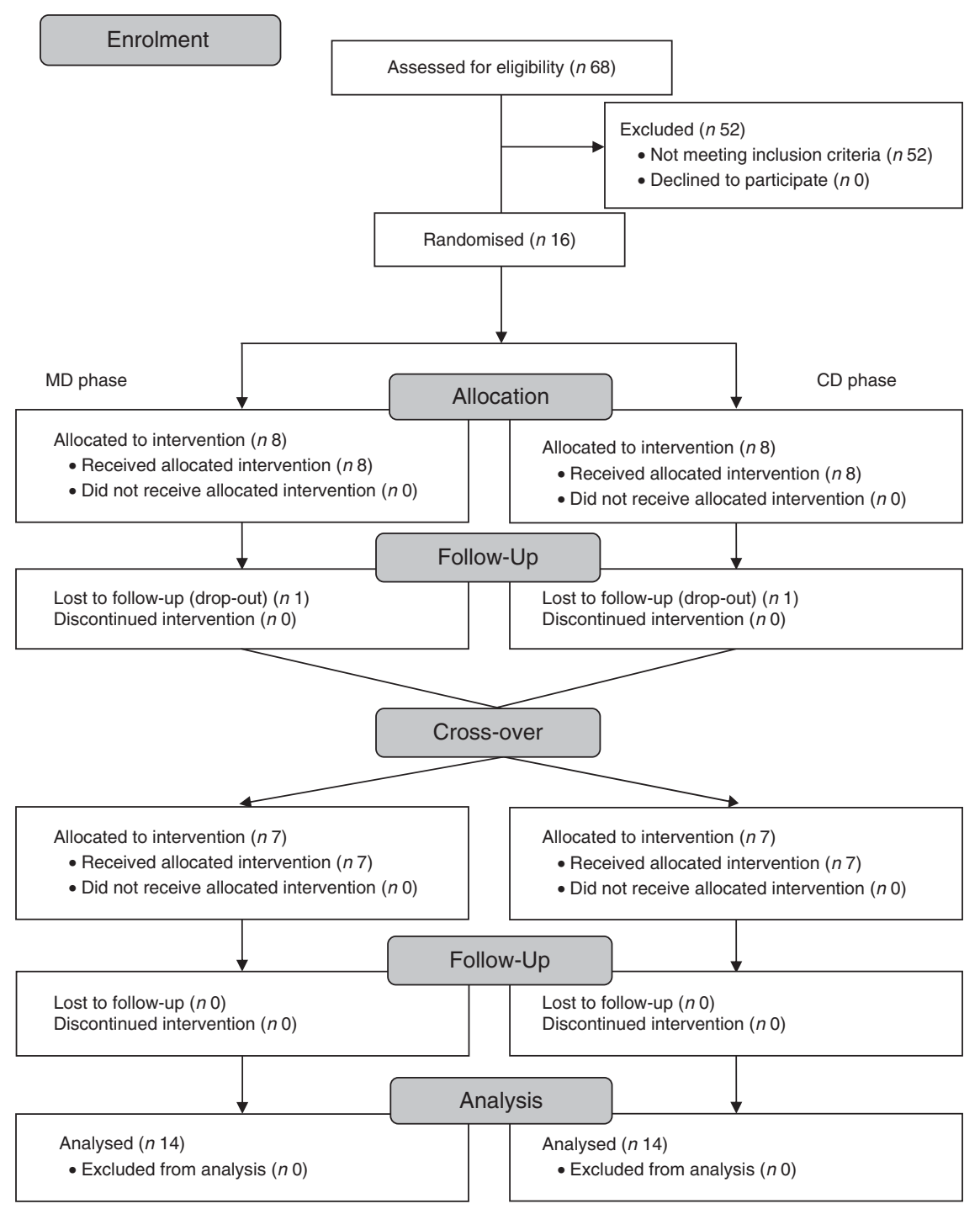

Fig. 2. Subjects flow throughout the study. MD, fat-free milk phase; $C D$, control phase.

\section{Metabolic syndrome components and cardiometabolic measures}

WC decreased after MD, whereas no change was observed after CD (intra-group comparison) (Table 3). Reduction in WC from baseline to 12 weeks was greater in MD than CD (inter-group comparison) (Table 3). Total cholesterol, LDL-cholesterol, SBP and DBP, and LAP index decreased after MD (intra-group comparison) (Table 3). HDL:LDL ratio was higher after MD (intra-group comparison) (Table 3). There were no changes on biochemical variables in the $\mathrm{CD}$, except from an increase in fasting glucose (intra-group comparison) (Table 3). Comparing changes from baseline to 12-week intervention, SBP, DBP and LAP index decreased in MD compared with CD (inter-group comparison) (Table 3).

\section{Calcium homoeostasis markers}

Serum Ca and P remained unchanged in both phases (intragroup comparison) (Table 3). Serum $\mathrm{Mg}$ and PTH decreased after MD, but there was no change after CD (intra-group comparison) (Table 3). Serum 25-hydroxyvitamin D was higher after MD and lower after CD (intra-group comparison) (Table 3). Changes in vitamin D, Mg and PTH from baseline to 12-week intervention differed between dietary phases (inter-group comparison) (Table 3).

\section{Discussion}

To our knowledge, this is the first study to investigate the effect of the increased consumption of Ca from fat-free milk on MetS components and cardiometabolic measures in subjects with T2DM. Our results indicate that the consumption of approximately three servings of fat-free milk and approximately $1200 \mathrm{mg}$ of $\mathrm{Ca} / \mathrm{d}(700 \mathrm{mg}$ of $\mathrm{Ca} / \mathrm{d}$ from breakfast shakes $+500 \mathrm{mg}$ of dietary $\mathrm{Ca}$ under free-living condition) during 12 weeks decreased some of the MetS components and cardiometabolic measures, such as WC, SBP, DBP and LAP index, compared with a low-Ca energy-restricted diet. In Brazil, average daily $\mathrm{Ca}$ intakes of $550 \mathrm{mg}$ ( $84 \%$ of inadequacy) and $477 \mathrm{mg}$ 
Subjects with type 2 diabetes and low habitual Ca intake

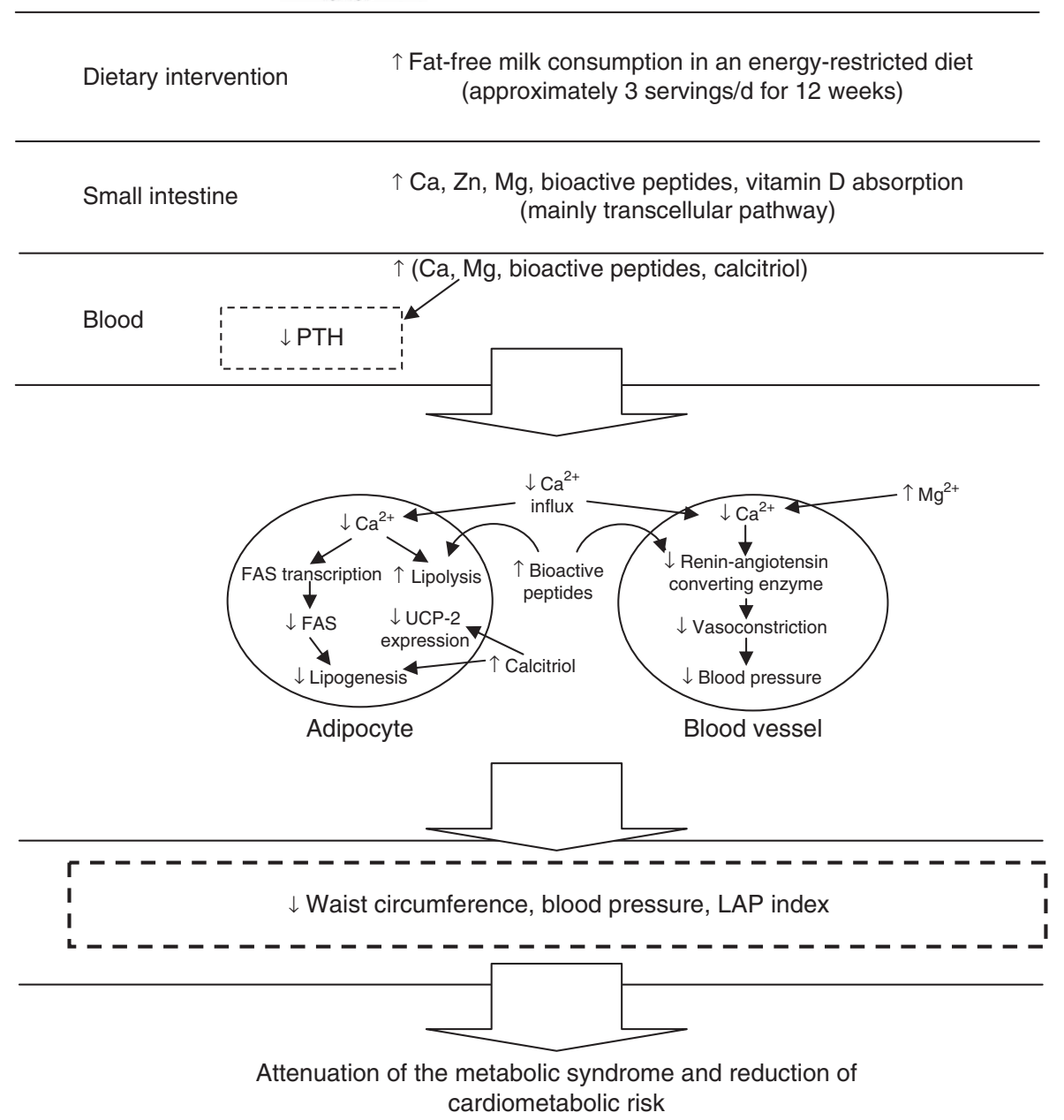

Fig. 3. Possible mechanisms that explain the effects of increased fat-free milk consumption associated with an energy-restricted diet on metabolic syndrome components and cardiometabolic outcomes, based on our results. FAS, fatty acid synthase; LAP, lipid accumulation product; PTH, parathormone; UCP-2, uncoupling protein 2.

(90.7\% of inadequacy) are estimated for adult men and women, respectively ${ }^{(25)}$. Possible mechanisms that may explain the effects of increased fat-free milk consumption associated with an energy-restricted diet on MetS components and cardiometabolic outcomes, based on our results, are presented in Fig. 3.

The results of some RCT also indicate that dietary $\mathrm{Ca}$ ( $>1100 \mathrm{mg} / \mathrm{d}$ ) from dairy product consumption decreased WC in adults ${ }^{(11,12)}$, but other authors did not find an inverse association between $\mathrm{Ca}$ /dairy intake and central adiposity ${ }^{(26,27)}$. Although overweight or obese subjects were also included in these clinical trials, the main differences between them were the habitual intake of $\mathrm{Ca}$ and the energy consumption (euenergetic or energy-restricted diets) during the studies. When the habitual intake of Ca was $>800 \mathrm{mg} / \mathrm{d}$, there was no effect on $\mathrm{WC}^{(26,27)}$. A threshold effect for $\mathrm{Ca}$ intake equivalent to approximately $600-800 \mathrm{mg} / \mathrm{d}$ has been proposed $^{(28)}$, probably because low habitual Ca consumers typically present higher absorption of ingested Ca because they use preferentially transcellular pathway (active transport) instead of paracellular pathway (passive transport $)^{(29)}$. In our study, the participants presented low-Ca consumption (mean intakes $<600 \mathrm{mg} / \mathrm{d}$ ) at baseline of both phases. A meta-analysis of fourteen RCT in 883 adults indicated that increasing dairy consumption only resulted in higher reduction in WC if energy-restricted diet was adopted compared with the consumption of conventional energy-restricted diets alone ${ }^{(8)}$. The reduction in WC observed in MD was an important result, as WC is a good marker of visceral fat accumulation and is useful for predicting $\mathrm{CVD}^{(11)}$.

MD phase also promoted greater reduction of SBP and DBP compared with the CD one. Some RCT indicated lower BP in response to dairy intervention ${ }^{(4,30)}$, whereas in other studies the increased consumption of dairy foods did not affect $\mathrm{BP}^{(27,31)}$. Crichton et al. ${ }^{(32)}$ suggest that the effects of dairy consumption 
on $\mathrm{BP}$ are clearly demonstrated only in people with high $\mathrm{BP}$ (SBP $>130 \mathrm{mmHg}$ and/or DBP $>85 \mathrm{mmHg}$ ). Low-fat dairy products and $\mathrm{Ca}$ supplementation equivalent to $1200 \mathrm{mg} / \mathrm{d}$ also contribute to reduce $\mathrm{BP}$, especially in people with habitual $\mathrm{Ca}$ intakes $<800 \mathrm{mg} / \mathrm{d}^{(9,31)}$. In our study, we offered fat-free milk; the subjects were low habitual Ca consumers and their baseline $\mathrm{BP}$ before increasing dairy consumption was slightly high (mean SBP $136.6 \mathrm{mmHg}$ and mean DBP $84.2 \mathrm{mmHg}$ ). Therefore, we observed a significant reduction of $16 \mathrm{mmHg}$ in SBP and $10.8 \mathrm{mmHg}$ in DBP. Furthermore, the improved BP control with fat-free milk consumption may be clinically relevant, as people with diabetes are more susceptible to $\mathrm{CVD}^{(21)}$.

In our study, there was a greater LAP index reduction in the MD phase compared with within the CD. However, the large difference in LAP baseline values between these two phases is a limitation. That index has been shown to predict incident T2DM and the MetS, and it is considered a better index than BMI in predicting cardiovascular risk ${ }^{(23)}$, and $\mathrm{T}_{2} \mathrm{DM}^{(33)}$. The LAP index is also associated with glucose tolerance ${ }^{(34)}$, and thus the lower LAP index after high-Ca diets could probably benefit diabetes control. The reduction in WC and in LAP index in MD suggests that this experimental phase promoted visceral adiposity reduction.

Beneficial effects of dairy product intake on MetS components and cardiovascular outcomes can be attributed to its $\mathrm{Ca}$ content ${ }^{(4,5)}$, but also to proteins ${ }^{(2)}$ and other minerals present in dairy products ${ }^{(35)}$. Dietary fat binds to $\mathrm{Ca}$ in the intestine and inhibits its absorption, favouring body weight loss ${ }^{(3)}$. However, the main effect of high-Ca diets is the decrease in calcitriol (1,25-dihydroxyvitamin D) and PTH concentrations, resulting in lower $\mathrm{Ca}$ influx into adipocytes, favouring the occurrence of lipolysis ${ }^{(36)}$. On the other hand, low-Ca diets increase calcitriol and PTH concentrations, resulting in $\mathrm{Ca}^{2+}$ influx into adipocytes. Increased intracellular $\mathrm{Ca}^{2+}$ activates lipogenesis and suppresses lipolysis, increasing body fat and inducing insulin resistance ${ }^{(36)}$. Calcitriol also inhibits the expression of adipocyte uncoupling protein 2 , reducing mitochondrial fatty acid transport and fat oxidation ${ }^{(37)}$. Therefore, the effects observed in this study may have been due to synergic dairy composition.

$\mathrm{Ca}$ intake may also interfere in BP. The increased $\mathrm{Ca}^{2+}$ influx into smooth muscle cells owing to low-Ca consumption can cause vasoconstriction and result in increased BP. Therefore, high-Ca diets seem to prevent Ca-mediated hypertension ${ }^{(2,38)}$. Disturbances in intracellular ions, such as increased $\mathrm{Ca}$ and decreased $\mathrm{Mg}$, which are common responses in low-Ca diets, lead to vasoconstriction, increased platelet aggregation and thrombosis, as well as insulin resistance ${ }^{(38)}$. In combination, $\mathrm{Mg}$ acts as a $\mathrm{Ca}$ antagonist on smooth muscle tone, blocking $\mathrm{Ca}^{2+}$ channels, and thus reducing vasoconstriction ${ }^{(39)}$. Milk protein content may also be responsible for its anti-hypertensive and anti-obesity effects. Milk protein inhibits the angiotensinconverting enzyme, consequently reducing $\mathrm{BP}^{(2)}$. In our study, besides the higher Ca content of MD breakfast shakes, both casein and whey protein (MD phase) may have contributed to lower SBP and DBP. On the other hand, the low-Ca and whey protein consumption (CD phase) did not affect BP. As hydrolysed casein is less absorbed ${ }^{(2)}$ and the Ca content of micellar casein (contains $70 \%$ of $\mathrm{Ca}$ in milk) could not be isolated ${ }^{(40)}$, we offered only whey protein to CD to match the Ca content of the breakfast shakes. However, it is difficult to distinguish which dairy component has the better effect on MetS components and cardiovascular risk, as dairy products are good sources of the above-mentioned nutrients.

A strength of our study was the randomised, controlled crossover design to assess the effects of high $\mathrm{Ca}$ from fat-free milk associated with an energy-restricted diet; hence, it reduces between-subject variability. We also controlled PAL and medication use throughout the study. Possible limitations of our study include MD dietary fibre intake increase (approximately $9.4 \mathrm{~g} / \mathrm{d}$ higher than $\mathrm{CD}$ ). However, we believe that this difference probably did not influence our results as it has been shown that a daily dietary fibre consumption of approximately $40 \mathrm{~g}$ is necessary to improve glycaemia ${ }^{(41)}$ and the consumption of $10 \mathrm{~g} / \mathrm{d}$ of fibre is not enough to increase weight loss ${ }^{(42)}$.

In conclusion, the consumption of about three servings of fatfree milk (700 mg of dietary additional $\mathrm{Ca} / \mathrm{d}$ ) associated with an energy-restricted diet for 12 weeks promoted greater decrease in WC, BP and LAP index than the control diet in adults with T2DM.

\section{Acknowledgements}

The authors thank Instituto Federal do Sudeste de Minas Gerais, Coordenação de Aperfeiçoamento de Pessoal de Nível Superior, Fundação de Amparo à Pesquisa do Estado de Minas Gerais, Conselho Nacional de Desenvolvimento Científico e Tecnológico and Bioclin ${ }^{\circledR}$, Quibasa Química Ltda.

For financial support, the authors thank Coordenação de Aperfeiçoamento de Pessoal de Nível Superior, Fundação de Amparo à Pesquisa do Estado de Minas Gerais, and Conselho Nacional de Desenvolvimento Científico Tecnológico.

The authors' contributions were as follows: J. M. G. G. designed the study, analysed and interpreted the data and wrote the manuscript. J. A. C. assisted in analysing the data. R. C. G. A. designed the study, interpreted the data and edited the manuscript. All authors read and approved the final manuscript.

The authors declare that there are no conflicts of interest.

\section{Supplementary material}

For supplementary material/s referred to in this article, please visit http://dx.doi.org/doi:10.1017/S0007114517003956

\section{References}

1. Visioli F \& Strata A (2014) Milk, dairy products, and their functional effects in humans: a narrative review of recent evidence. Adv Nutr 5, 131-143.

2. Dugan CE \& Fernandez ML (2014) Effects of dairy on metabolic syndrome parameters: a review. Yale J Biol Med 87, 135-147.

3. Jacobsen R, Lorenzen J, Toubro S, et al. (2005) Effect of shortterm high dietary calcium intake on 24-h energy expenditure, fat oxidation, and fecal fat excretion. Int J Obes 29, 292-301.

4. Wang L, Manson JE, Buring JE, et al. (2008) Dietary intake of dairy products, calcium, and vitamin $\mathrm{D}$ and the risk of hypertension in middle-aged and older women. Hypertension 51, 1073-1079. 
5. Tong X, Dong JY, Wu ZW, et al. (2011) Dairy consumption and risk of type 2 diabetes mellitus: a meta-analysis of cohort studies. Eur J Clin Nutr 65, 1027-1031.

6. Nettleton JA, Steffen LM, Mayer-Davis EJ, et al. (2006) Dietary patterns are associated with biochemical markers of inflammation and endothelial activation in the Multi-Ethnic Study of Atherosclerosis (MESA). Am J Clin Nutr 83, 1369-1379.

7. Alexander DD, Bylsma LC, Vargas AJ, et al. (2016) Dairy consumption and CVD: a systematic review and metaanalysis. Br J Nutr 115, 737-750.

8. Abargouei AS, Janghorbani M, Salehi-Marzijarani $\mathrm{M}$, et al. (2012) Effect of dairy consumption on weight and body composition in adults: a systematic review and meta-analysis of randomized controlled clinical trials. Int J Obes 36, 1485-1493.

9. Ralston RA, Lee JH, Truby H, et al. (2012) A systematic review and meta-analysis of elevated blood pressure and consumption of dairy foods. J Hum Hypertens 26, 3-13.

10. Pasin G \& Comerford KB (2015) Dairy foods and dairy proteins in the management of type 2 diabetes: a systematic review of the clinical evidence. Adv Nutr 6, 245-259.

11. Zemel MB, Richards J, Mathis S, et al. (2005) Dairy augmentation of total and central fat loss in obese subjects. Int J Obes Relat Metab Disord 29, 391-397.

12. Torres MR \& Sanjuliani AF (2013) Effects of weight loss from a high-calcium energy-reduced diet on biomarkers of inflammatory stress, fibrinolysis, and endothelial function in obese subjects. Nutrition 29, 143-151.

13. Alberti KG, Eckel RH, Grundy SM, et al. (2009) Harmonizing the metabolic syndrome: a joint interim statement of the International Diabetes Federation Task Force on Epidemiology and Prevention; National Heart, Lung, and Blood Institute; American Heart Association, World Heart Federation, International Atherosclerosis Society; and International Association for the Study of Obesity. Circulation 120, 1640-1645.

14. Strunkard AJ \& Messic S (1985) The Three Factor Eating Questionnaire to measure dietary restraint, desinhibition, and hunger. J Psychosom Res 29, 71-83.

15. Pardini R, Matsudo S, Araujo T, et al. (2001) Validation of the International Physical Activity Questionnaire (IPAQ version 6): pilot study in Brazilian young adults. Rev Bras Cien Mov 9, 45-51.

16. Ribeiro AB \& Cardoso MA (2002) Construção de um questionário de freqüência alimentar como subsídio para programas de prevenção de doenças crônicas não transmissíveis (Development of a food frequency questionnaire as a tool for programmes of chronic disease prevention). Rev Nutr 15, 239-245.

17. Monteiro JP, Pfrimer K, Tremeschin MH, et al. (2007) Consumo Alimentar: Visualizando porções. Rio de Janeiro: Guanabara Koogan.

18. Black AE (2000) Critical evaluation of energy intake using the Goldberg cut-off for energy intake:basal metabolic rate. A practical guide to its calculation, use and limitations. Int J Obes Relat Metab Disord 24, 1119-1130.

19. Food and Agriculture Organization, World Health Organization \& United Nations University (1985) Energy and Protein Requirements. Report of a Joint FAO/WHO/UNU Consultation. Technical Report Series, no. 724. Geneva: WHO.

20. Trumbo P, Schlicker S, Yates AA, et al. (2002) Dietary reference intakes for energy, carbohydrate, fiber, fat, fatty acids, cholesterol, protein and amino acids. J Am Diet Assoc 102, 1621-1630.

21. American Diabetes Association (2016) Standards of medical care in diabetes - 2016. Diabetes Care 39, S1-S108.

22. Wang J, Thornton JC, Bari S, et al. (2003) Comparisons of waist circumferences measured at 4 sites. Am J Clin Nutr 77, 379-384.
23. Kahn HS (2005) The "lipid accumulation product" performs better than the body mass index for recognizing cardiovascular risk: a population-based comparison. BMC Cardiovasc Disord 5, 26.

24. Mera R, Thompson H \& Prasad C (1998) How to calculate sample size for an experiment: a case-based description. Nutr Neurosci 1, 87-91.

25. Araujo MC, Bezerra IN, Barbosa FS, et al. (2013) Consumo de macronutrientes e ingestão inadequada de micronutrientes em adultos (Macronutrient consumption and inadequate micronutrient intake in adults). Rev Saúde Pública 47, 177s-189s.

26. Wennersberg MH, Smedman A, Turpeinen AM, et al. (2009) Dairy products and metabolic effects in overweight men and women: results from a 6-mo intervention study. Am J Clin Nutr 90, 960-968.

27. Jones KW, Eller LK, Parnell JA, et al. (2013) Effect of a dairyand calcium-rich diet on weight loss and appetite during energy restriction in overweight and obese adults: a randomized trial. Eur J Clin Nutr 67, 371-376.

28. Dougkas A, Reynolds CK, Givens ID, et al. (2011) Associations between dairy consumption and body weight: a review of the evidence and underlying mechanisms. Nutr Res Rev $\mathbf{2 4}$, $72-95$.

29. Kopic S \& Geibel JP (2013) Gastric acid, calcium absorption, and their impact on bone health. Physiol Rev 93, 189-268.

30. van Meij LEC \& Mensink RP (2011) Low-fat dairy consumption reduces systolic blood pressure, but does not improve other metabolic risk parameters in overweight and obese subjects. Nutr Metab Cardiovasc Dis 21, 355-361.

31. van Mierlo LA, Arends LR, Streppel MT, et al. (2006) Blood pressure response to calcium supplementation: a metaanalysis of randomized controlled trials. I Hum Hypertens 20, 571-580.

32. Crichton GE, Howe PRC, Buckley JD, et al. (2012) Dairy consumption and cardiometabolic health: outcomes of a 12-month crossover trial. Nutr Met 9, 19.

33. Kahn HS (2006) The lipid accumulation product is better than BMI for identifying diabetes: a population-based comparison. Diabetes Care 29, 151-153.

34. Wehr E, Pilz S, Boehm BO, et al. (2011) The lipid accumulation product is associated with increased mortality in normal weight postmenopausal women. Obesity 19, 1873-1880.

35. Rice BH, Quann EE \& Miller GD (2013) Meeting and exceeding dairy recommendations: effects of dairy consumption on nutrient intakes and risk of chronic disease. Nutr Rev 71, 209-223.

36. Zemel MB, Shi H, Greer B, et al. (2000) Regulation of adiposity by dietary calcium. FASEB J 14, 1132-1138.

37. Zemel MB, Teegarden D, Loan MV, et al. (2000) Dairy-rich diets augment fat loss on an energy-restricted diet: a multicenter trial. Nutrients 1, 83-100.

38. Resnick L (1999) The cellular ionic basis of hypertension and allied clinical conditions. Prog Cardiovasc Dis 42, 1-22.

39. Bo S \& Pisu E (2008) Role of magnesium in cardiovascular disease prevention, insulin sensitivity and diabetes. Curr Opin Lipidol 19, 50-56.

40. Gaucheron F (2005) The minerals of milk. Reprod Nutr Dev 45, 473-483.

41. Silva FM, Kramer CK, de Almeida JC, et al. (2013) Fiber intake and glycemic control in patients with type 2 diabetes mellitus: a systematic review with meta-analysis of randomized controlled trials. Nutr Rev 71, 790-801.

42. Du H, van der A DL, Boshuizen HC, et al. (2010) Dietary fiber and subsequent changes in body weight and waist circumference in European men and women. Am J Clin Nutr $\mathbf{9 1}$, 329-336. 